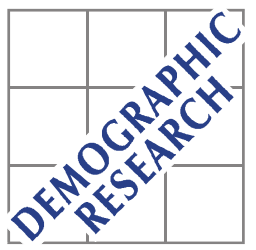

Demographic Research a free, expedited, online journal

of peer-reviewed research and commentary in the population sciences published by the Max Planck Institute for Demographic Research

Konrad-Zuse Str. 1, D-18057 Rostock · GERMANY

www.demographic-research.org

DEMOGRAPHIC RESEARCH

VOLUME 17, ARTICLE 22, PAGES 655-678

PUBLISHED 20 DECEMBER 2007

http://www.demographic-research.org/Volumes/Vol17/22/

DOI: 10.4054/DemRes.2007.17.22

Research Article

\title{
Geographical distances between adult children and their parents in the Netherlands
}

\section{Francesca Michielin}

\section{Clara H. Mulder}

Special Collection 6: Interdependencies in the Life Course, edited by Hill Kulu and Nadja Milewski.

(C) 2007 Michielin \& Mulder

This open-access work is published under the terms of the Creative Commons Attribution NonCommercial License 2.0 Germany, which permits use, reproduction \& distribution in any medium for non-commercial purposes, provided the original author(s) and source are given credit.

See http:// creativecommons.org/licenses/by-nc/2.0/de/ 


\section{Table of Contents}

1 Introduction $\quad 656$

$2 \quad$ Theoretical background 657

2.1 The influence of the characteristics of the family of origin 657

2.2 The influence of life-course events and their timing 659

2.3 The influence of other individual characteristics 660

3 Data and methods $\quad 661$

$4 \quad$ Results 667

4.1 The influence of the characteristics of the family of origin 667

4.2 The influence of life-course events and their timing 669

4.3 The influence of other individual characteristics 669

$\begin{array}{lll}5 & \text { Conclusions } & 671\end{array}$

$\begin{array}{lll}6 & \text { Acknowledgements } & 673\end{array}$

$\begin{array}{ll}\text { References } & 674\end{array}$ 


\title{
Geographical distances between adult children and their parents in the Netherlands
}

\author{
Francesca Michielin ${ }^{1}$ \\ Clara H. Mulder ${ }^{2}$
}

\begin{abstract}
We investigate the determinants of geographical distances to parents. We focus on the role of family members who live outside the household (the parents themselves, and siblings), and on the distinction between the effects of life events and effects related to the timing with which these events have been experienced in the life course. We use data from the Netherlands Kinship Panel Study and linear regression models on the logarithm of distance. We find that life-course characteristics are much more important to the distance to parents than parental characteristics. Sibling characteristics, most notably the presence of a sister, also have an impact on this distance.
\end{abstract}

\footnotetext{
${ }^{1}$ University of Amsterdam Department of Geography, Planning and International Development Studies, Nieuwe Prinsengracht 130, NL-1018 VZ Amsterdam. E-mail: F.Michielin@uva.nl

${ }^{2}$ University of Amsterdam Department of Geography, Planning and International Development Studies, Nieuwe Prinsengracht 130, NL-1018 VZ Amsterdam. E-mail: C.H.Mulder @ uva.nl
} 


\section{Introduction}

Despite the proliferation of internet and communication technology, geographical distance between family members is still of major importance in the intensity and shape of contacts among them. Even today, distance turns out to be one of the most powerful variables explaining the provision of care and support in family networks (see for example Bian et al. 1998).

The importance of family ties might lead people to refrain from moving further away from family members or to move closer to them. At the same time, there are many potential triggers during the life course for moving, related for example to educational attainment and the labor market career. The individual and family dimensions of the life course are thus connected, and individual choices oriented towards reaching personal goals might compete or interfere with the desire to maintain family solidarity (Bengtson 2001).

Because of the strong negative link between distance and the provision of support, it is no surprise that the determinants of intergenerational proximity, or the distances between adult children and their parents, have gained so much research attention since the 1990s (see Clark and Wolf 1992, Rogerson et al. 1993 1997, Bian et al. 1998, Glaser and Tomassini 2000, Shelton and Grundy 2000, Choi 2003, Fransson and Teeland 2004, Mulder and Kalmijn 2006, Van Diepen and Mulder 2006, Malmberg and Pettersson 2007). Previous research has focused mainly on individual, household, and macro determinants of the geographical distances between generations. The studies stress the major part that life-course events play in residential choice, and therefore also on distance: education, the labor-market position, and the household situation were found to have an important impact on the distance between family members.

In the research reported thus far, two sets of determinants have received little attention, even though they are arguably likely to be important with respect to distances between generations. The first set is related to the influence of the characteristics of the family as a whole, including the characteristics of family members who live outside the household of the individuals under study. Naturally, when explaining the distance between a parent and a child, it is important to take the characteristics of both the parent and the child into account. The characteristics and locations of siblings are also likely to be important. Not only are siblings alternative providers or receivers of support, but the family of origin also constitutes an important component of an individual's social capital. The family of origin is therefore a potential reason for inertia or for aiming at proximity to other family members. The lack of attention paid to date to the characteristics of family members outside the household is probably partly the result of the paucity of suitable data. Not many datasets contain information on both the respondent and other family members, particularly those living outside the household. 
The second set of under-researched determinants is the timing with which life events have been experienced. Life events have an impact on shaping the distances between generations, but their impact is likely to depend on the life-course stage in which the event took place. Research on other aspects of residential histories has demonstrated that a distinction between the occurrence of events and their timing is fruitful to gain a better understanding of housing dynamics (Feijten 2005).

The aim of this paper, therefore, is to provide a better understanding of the factors affecting the geographical distance from adult children who live independently to their parents, focusing specifically on the role of other family members living outside the household (parents and siblings), and on the distinction between the effects of life course events and effects related to the timing at which life course events are experienced.

We have used data from the Netherlands Kinship Panel Study for the analysis. These data offer a unique opportunity to simultaneously consider detailed geographical information about the place of residence of multiple family members together with detailed individual information. Using linear regression models of the logarithm of distance, we have investigated which factors are associated with a shorter or longer distance between adult children and their parents. We paid particular attention to the selection of respondents: To avoid our model reflecting the determinants of leaving the parental home instead of those of geographical separation, we restricted our analysis to those ages in which the majority of respondents would have already left home. In addition, we controlled for any remaining selection effects using a Heckman selection model: We checked whether the selection of children not co-residing with their parents resulted in biased parameter estimates.

\section{Theoretical background}

\subsection{The influence of the characteristics of the family of origin}

In analyzing the factors influencing the geographical distance between parents and children, the importance of the family as a whole has to be considered. For the younger generation (from which the respondents in our analysis have been taken), this is the family of origin. Family members constitute an essential part of an individual's social capital, and their presence increases the value associated with a specific location. In Da Vanzo's (1981) terms, the presence of family members is part of location-specific capital (the economic and social capital that is tied to a specific location). The presence of location-specific capital increases the cost of moving away from a location, and it increases the benefits of staying in or moving towards that location. 
The literature referring to family solidarity and family support (Rossi and Rossi 1990, Bengston and Roberts 1991, Bian et al. 1998) has drawn attention to the role of geographical distances in supporting exchange, making it clear that proximity facilitates contact and support. The cost of living far away from family members is, therefore, arguably greater when the need for support or the preference for contact with the family members involved is greater. In response to emerging needs, geographical distances can be reduced by a move of some family members (Silverstein 1995, Rogerson et al. 1997), as in the case of elderly migration when elderly parents move closer to one of the children to receive more support (Longino et al. 1991, Serow and Sly 1991). The need for support or contact might influence not only the distance between parents and children, but also the expectations of the level of support and contact. As Rossi and Rossi (1990) have shown, kinship norms are particularly strong between parents and children.

Specific parental characteristics are likely to indicate the extent to which a short distance to one or more children is important. The parental educational level can be considered as a proxy for economic resources, and as such represents the ability to buy care on the market: The higher the socio-economic status of the elderly, the lesser the need for proximity to their children. A poor health situation also indicates a greater need for support. Given that a person's health situation tends to deteriorate with age, we would expect children with older parents to live closer to them than would children with younger parents. A parent who becomes a widow or widower is also likely to need support.

The presence and location of siblings are also likely to be important. Being an only child may be associated with shorter distances to the parents, since there are no other siblings who could help in case of need. Conversely, having many siblings may allow the responsibility for caregiving to be shared among more people, possibly decreasing individual involvement (Klein Ikkink et al. 1999). In addition, the literature on family support has drawn attention to inequity among siblings in caregiving, which might be reproduced in geographical distances. Siblings differ with respect to their feelings of obligation toward their parents and the expectations the older generation have of them. Daughters tend to give more help to elderly parents than do sons, since caregiving is usually a female task (Spitze and Logan 1990, Sarkisian and Gerstel 2004). Not only actual behavior in case of need, but also general expectations of the provision of help differ between the two sexes and with family composition. Siblings place higher expectations on sisters to provide care than on brothers, also using the argument that the parents' preferences are being reflected (Ingersoll-Dayton et al. 2003). The presence of a sister (who could in principle take care of the parents in case of need) might lower the reluctance to move away from the parents. 
Concerning the location of siblings, two alternative hypotheses can be put forward. On the one hand, we might expect the presence of a sibling close to the parents to be associated with a longer distance. The feeling of personal responsibility towards one's parents and concern about distance might be reduced if one knows that a sibling lives close to the parents. On the other hand, there might be some clustering of behavior within the same family, resulting in dispersed or less dispersed networks of siblings. The possible reasons for this clustering are diverse. First, siblings might share characteristics that in turn influence their distance to the parents. For example, higher education is transmitted between generations and therefore frequently shared between siblings. Second, the greater the number of family members who live close to each other, the greater the location-specific capital of such a location. Thus proximity might become even more appealing. Third, regional or local differences in employment opportunities, educational opportunities, or the strength of local communities might lead families living in some locations to become more dispersed than in others.

The availability of jobs and educational opportunities in the residential location during childhood is partly reflected in the degree of urbanization. People who lived in less urbanized areas during their childhood reportedly tend to live further away from their parents (Lee et al. 1990, Lin and Rogerson 1995), because they are likely to have moved to an urban area to find a job or to attend an educational institution. Those already living in a more urbanized area experience less need to move for reasons of their educational or working career (Mulder and Kalmijn 2006).

\subsection{The influence of life-course events and their timing}

During the life course, individuals experience many events that may necessitate or hamper long-distance moves, or that may lead to a change in the desirability of proximity to parents. The impact of life-course events might differ according to the timing at which such events are experienced. When the events are experienced in an early phase of life, we expect their impact to be greater. As Rogerson and colleagues (1993) demonstrated, if we consider a series of moves in random directions, the average distance between family members would increase with the number of moves made. Thus, greater distance to the parents can be expected for those who left the parental home at an early age. This is because they would have had more time to make multiple moves than would those who left home later. Following this reasoning, we can expect substantially more time spent in situations enhancing migration to be associated with a longer distance to parents, whereas spending time in situations hampering migration would be associated with shorter distance. For situations that are irreversible (such as having children) or not often reversed in practice (such as home-ownership; transitions 
from ownership to rent are not common except among older people and divorcees), the timing of the first transition forms a good indication of the time spent in the situation. This assumption would probably also hold for marriage, but possibly not for unmarried cohabitations, because these are often short-lived.

Having children leads to stronger ties to the place of residence and to a smaller likelihood of moving (Long 1972, Mincer 1978, and many later studies). Having children might also lead to an increased desire to live close to the parents (or to parentsin-law), or a growing desire among the parents to live close by. This desire is associated with the potentially supportive role grandparents may play in raising younger children and with their desire to spend time with and participate in the life of the younger generation (Lin and Rogerson 1995).

In many countries, including the Netherlands, homeowners are much less likely to migrate than renters (Helderman, Van Ham and Mulder 1996). In some cases, moreover, the parents might have helped to purchase the home, potentially influencing its location: Tomassini et al. (2003) found that in Italy such an economic transfer is associated with greater proximity between generations. Homeowners, particularly those who became homeowners early in life, are therefore expected to live closer to their parents than renters. The role of entering the labor market at an early age is not so clear. On the one hand, having a job allows independence from the parental home, and the sooner this happens, the greater are the chances of moving and moving far away. On the other hand, those who entered the labor market at an early age probably also left school early and started work in a less prestigious job for which it was not necessary to move. In the data, we have no separate measurement for the timing of leaving school.

\subsection{The influence of other individual characteristics}

Higher levels of education are associated with longer distances between children and their parents as a result of the different mechanisms in operation (Rogerson et al. 1993). Attending higher education may have required a long-distance move (Dahmann 1982), and people who left the parental home for educational purposes may also be more willing to live farther away from home in general (Rogerson et al. 1993) or they may have developed more independent attitudes during their studies (Beets et al. 1999). According to human-capital theory, highly-educated people have made greater investments in their education than others and are thus more likely to undertake the effort of moving to increase the return on their human capital (Sjaastad 1962). Moves can then frequently cover a long distance, because the specialized labor market is less widespread and more geographically restricted to a few big cities. For the same reason, 
the higher the social class, the longer the distance between parents and children tends to be (see, for example, Warnes 1986).

Singles may be in need of more contact with their families, but they are also more mobile. Residential decisions of those with a stable partner might result from a bargaining process in which the partners simultaneously take into account the location of parents and in-laws. For this category then, a potential explanation for distance to parents is distance to parents-in-law. Compared with those who have a partner or are unmarried singles, divorced and widowed people may be in need of more contact, and this need may lead them to choose a residential location close to their parents. This idea is supported by research into the residential careers of divorcees (Dieleman and Schouw 1989), which suggests that returning to live close to the parents might be a short-term strategy for those who face the consequences of a disruption.

It is likely that being seriously ill increases the reluctance to move far away and the likelihood to move closer (Mulder and Kalmijn 2006). Being an immigrant is also associated with shorter distances between generations, at least if both generations live in the same host country. The family of origin often constitutes the main support network for migrants, it is frequently responsible to help find a first location upon arrival (Bartel 1989, Borjas 1998, Zavodny 1998, Aslund 2005). In addition, solidarity norms in specific non-western groups are stronger than in the native Dutch population (Abraham 1996, Yerden 2000).

The older the individual, the greater is the probability that residential moves have taken place, and that the present distance between generations is large (Rogerson et al. 1993). Thus, net of the age of the parents, we expect a positive age effect for the younger generation. What kind of difference between the genders we should expect is not obvious. Women tend to perform more caregiving tasks and are subject to stronger norms regarding contact and support (Rossi and Rossi 1990). But at the same time, women are more likely to move to their partner's residential location upon partnership formation than men (Mulder and Wagner 1993, Boyle et al. 1998) and more likely to move due to their husbands' careers (Mincer 1978, Cooke 2003).

\section{Data and methods}

We have employed data derived from the first wave of the Netherlands Kinship Panel Study (NKPS, Dykstra et al. 2005). This survey was conducted in 2002-2003 and contains information about a representative sample of the Netherlands population aged 18-79 not living in institutions. Besides the general interest in kin relationships, one of the main features of this new dataset is its attention to geographical information: The postcodes of the residential locations of the main respondent, his/her parents, siblings, 
and children have been collected when available. In addition, detailed background characteristics of the main respondent and events taking place during his or her life course have been gathered. Unfortunately, no retrospective information on the housing history (such as the number of moves during the life course and their timing) is available.

Because we want to focus on adults and study their geographical distance to the parents in the Netherlands, we selected respondents aged between 26 and 50 with at least one parent still alive and living in the country. There were two reasons for choosing respondents from the younger generation. First, people are much more mobile geographically at younger ages than after their children have left home, so it is much more important to use information about individual life courses for the younger generation than for the older. Second, using respondents from the younger generation provides the opportunity to study parent-child relationships for parents of all ages rather than just for those under 80 years of age.

To prevent our model from reflecting the determinants of leaving the parental home rather than those of geographical distance, we did not include age categories in which co-residence with the parents is common (the percentage of co-residing adults only drops below 10 percent from the age of 26 - see Table 1 ). However, even with this age selection, it is important to distinguish between those who co-reside with their parents and those living independently: Co-residence represents not only a very short distance, but also a different household situation. Nowadays, the preferred situation for adults and their parents is largely for intimacy at a distance in separate households; the co-residence of different generations is uncommon and may be associated with special circumstances. For some, co-residence will follow from postponement in leaving home. Others might belong to the small category of people who never leave the parental home, for example because of a shared farm or firm, the inability of either of the generations to maintain a household of their own, or a preference for co-residence. Still others might have returned to their parental home temporarily because of separation from their partner or troubles with housing. And some might have taken their parents into their home to care for them. As an analytical strategy, therefore, we restricted our attention to adults living independently and analyzed the influence various factors have on the (log)distance to their parents. In addition, we performed a formal check in the multivariate model to see that selecting only children living in separate homes did not produce biased results. Because the results obtained with the Heckman selection model (Heckman 1979) were consistent with those of a simple regression model, we present only the simple model. The factors that have a significant impact on parent-child distance were the same, and the variation in the parameter estimates was only found in the second digit after the decimal point. In addition, the correlation between the selection equation and the substantive equation was positive (0.19) but not significant 
(the p-value was 0.54 ), suggesting that the decision to live independently and the choice of residential location are independent.

Table 1: Percentage of children living in parental home by age group

\begin{tabular}{lrrr}
\hline \multirow{2}{*}{ Age group } & \multicolumn{3}{c}{ Adults living in parental home } \\
\cline { 2 - 4 } & Absolute number & Share in \% & Total number of cases \\
\hline 18 to 20 & 132 & 77.6 & 170 \\
21 to 25 & 103 & 27.5 & 374 \\
26 to 30 & 37 & 5.9 & 631 \\
31 to 35 & 22 & 2.7 & 820 \\
36 to 40 & 24 & 2.9 & 830 \\
41 to 45 & 19 & 2.6 & 727 \\
46 to 50 & 14 & 2.5 & 566 \\
Total & 351 & 8.5 & 4118 \\
\hline
\end{tabular}

Source: Calculations based on NKPS 2002/03.

The dependent variable is the logarithm of the distance in kilometers. The logarithmic transformation was performed because it is likely that the various factors do not have the same role for short and long distances: A particular independent variable may matter to a difference between 10 and 20 kilometers, but less so to a difference between 110 and 120 . It is also likely that after a certain threshold, an increase in distance might not have an impact on the possibilities of contact and support. To check whether or not our results strongly depend on individuals who live at long distances from their parents, we performed additional models, in which the distances exceeding a certain threshold $(200 \mathrm{~km}, 150 \mathrm{~km}, 100 \mathrm{~km}, 50 \mathrm{~km})$ were set to the value of the threshold. All results proved to be robust to alternative definitions of the dependent variable: Differences in the magnitude and significance of the parameters were negligible. If the parents did not live together (about 400 cases), the distance to the parent living closest has been used. Descriptive statistics of the dependent and independent variables are presented in Table $2 \mathrm{a}$ and $2 \mathrm{~b}$.

The educational level of the parents has been measured as the highest level of education of the two parents, classified in low (primary education or lower secondary), medium (higher secondary or vocational), or higher education (university). The age of the oldest parent was used to specify whether the parents were young (younger than 60 ), middle-aged, or old (older than 80). In describing the parental household situation, we distinguished between two parents alive and living together, two parents alive but not living together, and only one parent alive. 
Michielin \& Mulder: Geographical distances between adult children and their parents in the Netherlands

Table 2a: Descriptive statistics, categorical variables

\begin{tabular}{|c|c|c|c|}
\hline Variable & $\begin{array}{r}\text { Share } \\
\text { in \% }\end{array}$ & $\begin{array}{r}\text { Mean distance to } \\
\text { parents }\end{array}$ & $\begin{array}{l}\text { Standard } \\
\text { deviation }\end{array}$ \\
\hline \multicolumn{4}{|l|}{ Characteristics of the family of origin } \\
\hline \multicolumn{4}{|l|}{ Education of parents } \\
\hline Primary/lower secondary & 60.3 & $21.1^{* * *}$ & 36.0 \\
\hline Upper secondary/higher vocational & 29.6 & 35.0 & 45.2 \\
\hline University & 10.1 & 34.9 & 44.6 \\
\hline \multicolumn{4}{|l|}{ Age of parents } \\
\hline$<60$ years & 20.2 & 24.9 & 39.4 \\
\hline $60-80$ years & 68.1 & 26.5 & 40.3 \\
\hline $81+$ years & 11.7 & 30.3 & 42.1 \\
\hline \multicolumn{4}{|l|}{ Parental household situation } \\
\hline Two parents living together & 34.7 & 26.5 & 39.7 \\
\hline Only one parent alive & 10.5 & 23.2 & 34.8 \\
\hline Two parents, not living together & 54.8 & 27.4 & 41.8 \\
\hline \multicolumn{4}{|l|}{ Proximity of siblings } \\
\hline Having no siblings & 3.8 & $22.3^{* * *}$ & 34.2 \\
\hline At least one sibling living close to the parents & 66.1 & 21.3 & 35.6 \\
\hline All siblings living far away from the parents & 28.4 & 42.5 & 48.4 \\
\hline Having siblings, but not knowing their location & 1.7 & 29.6 & 44.2 \\
\hline \multicolumn{4}{|l|}{ Siblings structure } \\
\hline Female, having only brother(s) & 16.9 & $24.9^{*}$ & 38.2 \\
\hline Female, no siblings & 3.2 & 23.7 & 36.8 \\
\hline Male, no siblings & 2.3 & 25.7 & 38.7 \\
\hline Male, only brother(s) & 11.2 & 30.3 & 43.5 \\
\hline Female, only sister(s) & 14.4 & 28.7 & 40.8 \\
\hline Male, only sister(s) & 9.4 & 30.2 & 42.0 \\
\hline Female, sister(s) and brother(s) & 25.0 & 27.7 & 41.2 \\
\hline Male, sister(s) and brother(s) & 17.6 & 26.8 & 41.5 \\
\hline \multicolumn{4}{|l|}{ Degree of urbanization at age 15} \\
\hline Not urbanized & 14.3 & $32.2^{* * *}$ & 47.2 \\
\hline Hardly urbanized & 26.1 & 24.4 & 36.5 \\
\hline Moderately urbanized & 21.4 & 27.5 & 40.0 \\
\hline Strongly urbanized & 23.9 & 27.3 & 41.4 \\
\hline Very strongly urbanized & 14.3 & 22.5 & 37.0 \\
\hline \multicolumn{4}{|l|}{ Life-course events } \\
\hline \multicolumn{4}{|l|}{ Left parental home early } \\
\hline No & 76.0 & $21.6 * * *$ & 35.4 \\
\hline Yes & 24.0 & 42.5 & 49.9 \\
\hline
\end{tabular}


Table 2a: (Continued)

\begin{tabular}{|c|c|c|c|}
\hline Variable & Share in \% & $\begin{array}{r}\text { Mean distance to } \\
\text { parents }\end{array}$ & $\begin{array}{l}\text { Standard } \\
\text { deviation }\end{array}$ \\
\hline \multicolumn{4}{|l|}{ Having children } \\
\hline No & 35.0 & $30.2^{* * *}$ & 42.0 \\
\hline Yes & 65.0 & 24.7 & 39.3 \\
\hline \multicolumn{4}{|l|}{ Early parent } \\
\hline No & 83.5 & $27.7^{\star \star *}$ & 40.9 \\
\hline Yes & 16.5 & 21.3 & 37.4 \\
\hline \multicolumn{4}{|l|}{ Ever owner } \\
\hline No & 29.3 & 26.4 & 40.8 \\
\hline Yes & 70.7 & 26.8 & 40.2 \\
\hline \multicolumn{4}{|l|}{ Early owner } \\
\hline No & 75.9 & $29.0^{* * *}$ & 42.0 \\
\hline Yes & 24.1 & 19.2 & 33.5 \\
\hline \multicolumn{4}{|l|}{ Early labor-market entry } \\
\hline No & 87.4 & $28.5^{* * *}$ & 41.6 \\
\hline Yes & 12.7 & 13.8 & 27.3 \\
\hline \multicolumn{4}{|c|}{ Other individual characteristics } \\
\hline \multicolumn{4}{|l|}{ Education } \\
\hline Up to primary & 2.9 & $15.5^{* * *}$ & 34.4 \\
\hline Lower secondary & 20.2 & 14.6 & 30.7 \\
\hline Upper secondary & 35.3 & 19.5 & 33.7 \\
\hline Higher vocational & 28.2 & 33.1 & 44.0 \\
\hline University & 13.4 & 52.5 & 47.8 \\
\hline \multicolumn{4}{|l|}{ Household situation } \\
\hline Single (not cohabiting) & 20.3 & 28.6 & 40.5 \\
\hline Cohabiting/married & 72.5 & 26.4 & 40.4 \\
\hline Single divorced & 6.5 & 23.6 & 39.5 \\
\hline Single widowed & 0.8 & 21.3 & 37.2 \\
\hline \multicolumn{4}{|l|}{ Having health problems } \\
\hline No & 97.0 & $27.0^{* *}$ & 40.5 \\
\hline Yes & 3.0 & 15.3 & 31.9 \\
\hline \multicolumn{4}{|l|}{ Being foreign born } \\
\hline No & 97.5 & $26.9^{* *}$ & 40.6 \\
\hline Yes & 2.5 & 15.6 & 30.0 \\
\hline \multicolumn{4}{|l|}{ Gender } \\
\hline Male & 40.8 & 27.4 & 41.6 \\
\hline Female & 59.2 & 26.1 & 39.5 \\
\hline
\end{tabular}

Source: Calculations based on NKPS 2002/03.

Significance level of the F-test for equal means in the subgroups: "*' $<5 \%$, ${ }^{\star \star \star *}<1 \%$, ${ }^{\text {****' }}<0.1 \%$. 
Table 2b: Descriptive statistics, continuous variables

\begin{tabular}{lcrrrr}
\hline Variable & Mean & $\begin{array}{r}\text { Standard } \\
\text { deviation }\end{array}$ & Minimum & Maximum & $\begin{array}{r}\text { Correlation with } \\
\text { distance }\end{array}$ \\
\hline $\begin{array}{l}\text { Characteristics of the } \\
\text { family of origin }\end{array}$ & & & & & \\
$\begin{array}{l}\text { Number of siblings } \\
\text { Other individual }\end{array}$ & 2.4 & 1.9 & 0.0 & 16.0 & -0.03 \\
characteristics & & & & & \\
Socio-economic status & 5.0 & 1.6 & 1.6 & 8.8 & 0.23 \\
Age & 37.7 & 6.8 & 26.0 & 50.0 & 0.04 \\
\hline
\end{tabular}

Source: Calculations based on NKPS 2002/03.

To explore the effects of siblings' characteristics on the residential decision of adult people, we estimated two different models to avoid that different aspects of sibling structure confound each other. The first model included detailed information on the sibling structure and number of siblings, distinguishing cases of absence of siblings, having only sister(s), only brother(s), or a mixed siblinghood, and combining this information with the gender of the respondent. In the second model the geographical location of each sibling was used to specify whether all siblings lived further than 10 kilometers away from the parents or whether at least one sibling lived closer (having no siblings was the reference category). We acknowledge that it is questionable to consider the distance between other siblings and the parents as exogenous while one's own distance to parents is a random variable: If individuals take siblings' locations into account, this will lead to interdependent choices. However, we do think that it is plausible that at a certain moment in time (most notably when they are about to relocate) individuals will consider their siblings' locations as given, because whereas individuals are able to decide about their own locations, they are probably not able to make their siblings move.

The measure for the degree of urbanization during the childhood of the respondent was derived from the address density of the residential location of the respondent when he or she was 15 years of age; the measure was categorized in five levels.

We reconstructed whether or not various life-course events had happened from the year of first-time homeownership, leaving the parental home, entering parenthood, and the first job, and whether or not they had take place in an early stage of the life course. To represent this sophistication, we calculated the age by which 25 percent of the population had experienced the event. Events experienced at a younger age were categorized as having happened early in the life course. The vast majority of respondents (over 97 percent) had had a first job and, given the selection of respondents, everyone had left the parental home. For the other life-course events, a 
separate dummy indicates whether the event had taken place or not. Unfortunately, we do not have complete information about the marital history of individuals or about the timing of leaving full-time education.

To measure the individual socio-economic situation, we used the highest educational level ever attended (in five levels) and a measure for representing the socioeconomic status: the International Socio-Economic Index (ISEI, which we divided by 10 to obtain larger parameter estimates; Ganzeboom, De Graaf, and Treiman 1992). The ISEI aims to measure the attributes of occupation that convert a person's education into income: The higher the ISEI score, the higher the socio-economic status of the occupation. For those not currently working, the ISEI was derived from the most recent previous occupation or - when not available - the average ISEI was assigned. In a separate model, we also tested for gender differences in education, the household situation, and life-course events. Many results obtained from this model are reported in the text, but not in the tables.

Furthermore, we included the gender of the respondent (dummy variable, man reference category), his or her age (continuous variable, both linear and quadratic effect), the household situation (single not cohabiting, cohabiting or married, divorced, widowed), having health problems, and being foreign-born.

\section{Results}

\subsection{The influence of the characteristics of the family of origin}

Some characteristics of the family of origin have a strong impact in shaping distances between adult children and their parents (Table 3). Surprisingly, however, parental characteristics seem not to be very important: Only the economic situation of the parents has a significant effect on the geographic distance between generations. Consistent with the hypothesis that the greater the need, the smaller the distance between family members, those with parents in better economic conditions (represented here via the educational level of the parents) live further away from them than do those with parents in less affluent circumstances. The distances for individuals with older parents are not found to differ from those of the others, possibly because we controlled for the age of the respondent, which is strongly correlated with the age of the parents. The same lack of explanatory power is related to the household situation of the elderly: Knowing that only one of the two parents is alive, or knowing that two are alive but not living together, does not add to the explanation of geographical distance between parents and children. Interpreting all these results we have to bear in mind that we are not studying the distance of the parents to their nearest adult child, which might be 
influenced more strongly by situations of great parental needs than our generic adult child-parent distance.

The sibling structure, combined with information about the location of brothers and sisters with respect to the parental residence, was found to be significantly related to the distance to parents. The hypothesis based on the idea that a reduced feeling of personal responsibility is associated with longer distances is supported only for daughters: Women with sisters live further away than males or women without sisters. The presence of siblings is not a clear determinant per se of the distance to the parents: Respondents who have no siblings occupy an intermediate position between those who have at least one sibling living close to the parents (they live closest) and those whose siblings are all living further than 10 kilometers from the parents (they show the longest distances). This result suggests that the hypothesis of the clustering of behavior is substantiated. Unfortunately, we have no information about the characteristics of the siblings, such as their level of education, that could help disentangle the mechanism underlying this finding. No effect is found of the total number of siblings.

The role of educational and job opportunities as potential triggers for a move is confirmed by the negative association between the level of urbanization of the place of residence during childhood and distance to parents in a later phase of life. Young people who lived in very rural areas are likely to have felt the necessity to move away from these areas to find a job or to complete education, resulting in longer distances to their parents during adulthood compared with those who spent their adolescence in places that have more job opportunities.

Table 3: Linear regression model of the logarithm of distance

\begin{tabular}{lcccr}
\hline Variable & $\begin{array}{c}\text { Model 1 } \\
\text { Parameter } \\
\text { estimate }\end{array}$ & $\begin{array}{c}\text { Standard } \\
\text { error }\end{array}$ & $\begin{array}{c}\text { Model 2 } \\
\text { Parameter } \\
\text { estimate }\end{array}$ & $\begin{array}{r}\text { Standard } \\
\text { error }\end{array}$ \\
\hline $\begin{array}{l}\text { Characteristics of the family of origin } \\
\text { Education of parents (ref.= primary/lower }\end{array}$ & & & & \\
secondary) & & & & \\
$\quad$ Upper secondary/higher vocational & $0.372^{* * *}$ & 0.068 & $0.291^{* * *}$ & 0.068 \\
$\quad$ University & $0.402^{* * *}$ & 0.101 & $0.299^{* *}$ & 0.100 \\
Age of parents (ref.=<60 years) & & & & \\
60-80 years & -0.007 & 0.093 & 0.022 & 0.092 \\
$\quad 81+$ years & 0.134 & 0.138 & 0.153 & 0.136 \\
$\begin{array}{l}\text { Parental household situation (ref.= two } \\
\text { parents living together) }\end{array}$ & & & & \\
$\quad$ Only one parent alive & & & & \\
Two parents, not living together & -0.124 & 0.068 & 0.093 & 0.067 \\
\hline
\end{tabular}


Table 3: (Continued)

\begin{tabular}{|c|c|c|c|c|}
\hline \multirow[b]{2}{*}{ Variable } & \multicolumn{2}{|c|}{ Model 1} & \multicolumn{2}{|c|}{ Model 2} \\
\hline & $\begin{array}{l}\text { Parameter } \\
\text { estimate }\end{array}$ & $\begin{array}{r}\text { Standard } \\
\text { error }\end{array}$ & $\begin{array}{l}\text { Parameter } \\
\text { estimate }\end{array}$ & $\begin{array}{r}\text { Standard } \\
\text { error }\end{array}$ \\
\hline \multicolumn{5}{|l|}{$\begin{array}{l}\text { Siblings structure } \text { (ref.= female, having } \\
\text { only brother(s)) }\end{array}$} \\
\hline Female, no siblings & 0.185 & 0.179 & & \\
\hline Male, no siblings & 0.209 & 0.204 & & \\
\hline Male, only brother(s) & 0.042 & 0.110 & & \\
\hline Female, only sister(s) & $0.364^{* * *}$ & 0.102 & & \\
\hline Male, only sister(s) & 0.216 & 0.116 & & \\
\hline Female, sister(s) and brother(s) & $0.228^{*}$ & 0.099 & & \\
\hline Male, sister(s) and brother(s) & 0.108 & 0.109 & & \\
\hline \multicolumn{5}{|l|}{ Proximity of siblings (ref.= having no siblings) } \\
\hline At least one sibling living $<10 \mathrm{~km}$ from parents & & & -0.263 & 0.155 \\
\hline All siblings living $>10 \mathrm{~km}$ from the parents & & & 0.434 ** & 0.156 \\
\hline Having siblings, but not knowing their location & & & -0.047 & 0.233 \\
\hline Number of siblings & -0.019 & 0.021 & 0.032 & 0.018 \\
\hline \multicolumn{5}{|l|}{$\begin{array}{l}\text { Degree of urbanization at age } 15 \\
\text { (ref.= not urbanized) }\end{array}$} \\
\hline Hardly urbanized & $-0.310^{* *}$ & 0.095 & $-0.299 * *$ & 0.094 \\
\hline Moderately urbanized & $-0.270 * *$ & 0.098 & $-0.266^{\star \star}$ & 0.096 \\
\hline Strongly urbanized & $-0.282^{* *}$ & 0.095 & $-0.265^{* *}$ & 0.093 \\
\hline Very strongly urbanized & $-0.383 * * *$ & 0.108 & $-0.402 * * *$ & 0.107 \\
\hline \multicolumn{5}{|l|}{ Life-course events } \\
\hline Left parental home early (ref.= no) & $0.671^{* * *}$ & 0.069 & $0.604^{* * *}$ & 0.068 \\
\hline Having children $(r e f .=$ no) & $-0.161^{*}$ & 0.082 & $-0.173^{*}$ & 0.081 \\
\hline Early parent $($ ref. $=$ no) & -0.008 & 0.086 & -0.014 & 0.085 \\
\hline Ever owner (ref.= no) & 0.007 & 0.076 & 0.023 & 0.075 \\
\hline Early owner (ref.= no) & $-0.174^{*}$ & 0.075 & -0.150 * & 0.074 \\
\hline Early labor market entry (ref.= no) & $-0.281^{* *}$ & 0.094 & $-0.269^{* \star}$ & 0.093 \\
\hline \multicolumn{5}{|l|}{ Other individual characteristics } \\
\hline \multicolumn{5}{|l|}{ Education (ref.= up to primary) } \\
\hline Lower secondary & -0.065 & 0.182 & -0.074 & 0.180 \\
\hline Upper secondary & 0.109 & 0.182 & 0.084 & 0.179 \\
\hline Higher vocational & $0.552^{* *}$ & 0.190 & 0.491 ** & 0.187 \\
\hline University & $1.180^{* * *}$ & 0.205 & $1.074^{* * *}$ & 0.202 \\
\hline \multicolumn{5}{|l|}{ Household situation (ref.= cohabiting/married) } \\
\hline Single (not cohabiting) & -0.029 & 0.091 & -0.063 & 0.090 \\
\hline Single divorced & $-0.255^{*}$ & 0.119 & $-0.244^{*}$ & 0.117 \\
\hline Single widowed & -0.121 & 0.326 & -0.171 & 0.321 \\
\hline Having health problems (ref.= no) & $-0.472^{* *}$ & 0.174 & $-0.509 * *$ & 0.171 \\
\hline Being foreign born (ref.= no) & -0.223 & 0.190 & -0.242 & 0.188 \\
\hline Age & -0.050 & 0.057 & -0.071 & 0.056 \\
\hline $\mathrm{Age}^{2}$ & 0.001 & 0.001 & 0.001 & 0.001 \\
\hline Female (ref. $=$ male) & & & 0.075 & 0.059 \\
\hline Constant & 1.510 & 1.076 & $2.133^{*}$ & 1.061 \\
\hline
\end{tabular}

Source: Calculations based on NKPS 2002/03; N=3574.

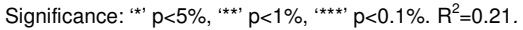




\subsection{The influence of life-course events and their timing}

Leaving the parental home at an early age is associated with longer distances to the parents, because more time is available to make multiple moves. Those who left home early are also more likely to have done so for reasons of education. Those who became homeowners early in the life course exhibit shorter distances than others. Homeownership appears to be important through its timing, but not intrinsically. The opposite holds for parenthood: No matter when the transition to parenthood took place, people with children live somewhat closer to their parents than do childless people. We might speculate that, whereas the effect of home-ownership mainly has to do with the time spent in a situation that hampers mobility and is thus coincidental, the effect of becoming a parent might have to do with the value that both the younger and the older generation attach to intergenerational proximity.

An early timing of the first job is associated with a shorter distance to the parents: Those who experienced early entry in the labor market are usually less well educated and are likely to have found a job in the area in which they reside. This constitutes an additional link with the current location, reducing the chances of further long-distance moves.

\subsection{The influence of other individual characteristics}

Individual characteristics are very important predictors of the distance between adult children and their parents. Our model shows that people who had completed higher education live much further away from their parents than do individuals who are less well educated, and this result holds after controlling for the effect of the socio-economic status of the respondent's occupation. At the same time, after controlling for level of education, those with a higher socio-economic status live further away from their parents than do individuals with a lower status. Whereas socio-economic status is associated with the characteristics of the labor market (the higher the status, the less widespread and more restricted geographically to the large cities are the job opportunities), the educational level also reflects the chances of having moved for educational reasons and the willingness to invest in human capital. Running an interaction between gender and educational level did not show any difference between genders: Education seems to have a similar impact for males and females.

Other life-course events also have an impact on distance. We found that married and widowed people tend to live at greater distances from their parents, while singles and particularly the divorced live closer. However, the only significant difference is between the married and the divorced. This finding confirms the idea that the 
importance of living close to the parents increases in circumstances of greater need, and that some divorcees might move closer to their parents. The results of additional models (not shown) revealed that this difference holds only for females: apparently, they are the most likely to put this option into practice.

The role of the family as a support network may also be the explanation of the shorter distance found for people who perceive their health situation as bad: In this situation living close to one's parents can be particularly appealing, since they could take care of an invalid child. It cannot, however, be ruled out that individuals with poor health are simply less likely to move long distances, irrespective of the residential location of the parents.

After controlling for all the other variables in the model, no effect was found for age or gender.

\section{Conclusions}

In this paper we have explored the geographical distance of adult children from their parents, paying particular attention to the role of the family of origin (characteristics of parents, siblings, and the location of the parental home) and to the distinction between the effects of events taking place during the life course and of their timing. An influence of the family of origin was hypothesized mainly because of the importance of support and contact among family members, which in turn is facilitated by geographical proximity. The timing of life-course events was expected to matter, because timing indicates the duration of the life-course span people have spent in situations enhancing or hampering migration.

The influence of parental characteristics was found to be of only limited importance. Neither the household situation of the parents nor their age had a statistically significant impact on the distance between generations. A significant impact was found for the parental level of education. This finding may indicate that the children of parents with a favorable economic situation, which facilitates buying care on the market, live further away from them than do others. But it is also possible that a high level of education indicates a greater likelihood of the parents having migrated after the children have left home. Furthermore, because of the educational levels of parents and their children are interlinked with each other, part of the effect of the child's educational levels might have shown up in the parameter for the parental level of education.

It should be borne in mind that in our model we are analyzing the distance between one specific adult and his or her parents, and not the availability of at least one child at a short distance from the elderly. If the latter had been the topic of analysis, parental 
characteristics might have appeared to be more influential. Furthermore, only a weak measurement of the support need of the older generation was available: age, not health. However, in an analysis of the average distance to adult children in which the respondents were taken from the older generation, health problems were not found to influence this distance (Mulder and Kalmijn 2006).

Interestingly, some impact of the sibling structure was found. The effect of the proximity of siblings to the parents, however, was not in line with the hypothesis that the availability of alternative providers of contact and care would be associated with longer distances. Rather, the hypothesis that clustering of behavior takes place within the same family was confirmed, since the results suggest the existence of dispersed networks of siblings. The similarity of characteristics influencing proximity among brothers and sisters (such as the level of education), the fact that the presence of family members increases the location-specific capital (the greater the number of family members in a place the higher its value) and regional or local differences in economic opportunities or in the strength of communities are all candidate causes for this finding. The effect of the number of siblings was small and insignificant. One finding, however, does suggest an effect of the presence of alternative sources of family care and contact: Females with at least one sister live further away from their parents than those who do not and males. Note, however, that no differences have been found between only children and people with siblings.

One other factor related to the family of origin was found to have a significant impact on the distance to parents: the degree of urbanization of the place of residence when the respondent was 15 years old. This impact, however, is more indicative of the educational and job opportunities available to the younger generation, and therefore of the necessity for that generation to migrate rather than of the need for contact or support.

Older people are considerably less mobile geographically than younger people, and therefore the current geographical dispersal of family members is mainly caused by the past geographical mobility of the younger generation. It is therefore no surprise that the distance to parents is associated much more strongly with individual characteristics than with the characteristics of the family of origin. This association is confirmed first of all by the explanatory power of life-course events as triggering or hampering subsequent mobility. As hypothesized, this explanatory power improves when we consider the timing of the events. Significant effects on the distance to parents were found from having left the parental home, having become a homeowner, and having entered the labor market at a young age. Having children is associated with a shorter distance to the older generation, but the distance is not further reduced when we take parenthood at an early age into account. 
Of the other individual characteristics, the level of education and the socioeconomic status were found to be of paramount importance to the distance between generations. These factors are obviously related to the greater willingness and necessity to migrate among those with higher education and higher-status jobs. Associations were also found with the household situation and the health of the younger generation: The divorced and those with health problems were found to live closer to their parents.

Interestingly, the overall findings seem to indicate that a need for support and contact might indeed lead to shorter distances - but for the need of the young generation rather than the old (a shorter distance for the divorced and those with health problems) or for the young as much as the old (a shorter distance to the parents for those with children, which also implies a shorter distance to those parents who are also grandparents). We have to be careful here, however. Even though the findings are in line with an interpretation that refers to a need for support or contact, we cannot be certain that such a need has in fact played a part in the location decision of any of the generations.

To attain more certainty about whether the need for contact or support really matters, future research should address many more issues associated with geographical distances between parents and children. The relocations of both generations need more attention to evaluate how distances evolve during the life course and ascertain which factors lead to a geographical convergence or divergence between parents and children. Another aspect worth considering is the location choice of married couples to understand their location with respect to the residence of both the parents and the parents-in-law. Finally, it would be interesting to explore the influence of the characteristics of multiple siblings rather than the influence of just one child. The Netherlands Kinship Panel Study, from which the data of the first wave were used for this paper, will offer better opportunities to address several of these issues after the second wave becomes available.

\section{Acknowledgements}

This paper is a part of the research program 'Residential choice in a family and sociospatial context', supported by NWO VICI grant no. 453-04-001.

The Netherlands Kinship Panel Study is funded by Grant 480-10-009 from the Major Investments Fund of the Netherlands Organization for Scientific Research (NWO) and by the Netherlands Interdisciplinary Demographic Institute (NIDI), Utrecht University, the University of Amsterdam, and Tilburg University.

We thank the participants of the leerzitje (a demography discussion group joining researchers from Amsterdam and Utrecht) for useful comments. 


\section{References}

Abraham, E. 1996. Oudere mensen zijn als bomen die schaduw geven: Oudere Marokkaanse vrouwen en mannen in de Nederlandse verzorgingsstaat [Older people are like trees providing shadow: Older Moroccan women and men in the Netherlands welfare state]. Amsterdam: Het Spinhuis.

Aslund, O. 2005. Now and forever? Initial and subsequent location choices of immigrants, Regional Science and Urban Economics 35: 141-165.

Bartel, A .P. 1989. Where do the new United States immigrants live?, Journal of Labor Economics 7: 371-391.

Beets, G. C. N., A. C. Liefbroer, and J. De Jong Gierveld. 1998. Changes in fertility values and behaviour: a life course perspective, in R. Leete (Ed.), Cultural and Temporal Variations in Values: Impact on Fertility Change. Oxford: Clarendon Press, pp. 100-120.

Bengston, V. L., and R. E. L. Roberts. 1991. Intergenerational solidarity in aging families: an example of formal theory construction, Journal of Marriage and the Family 53: 856-870.

Bengtson, V. L. 2001. Beyond the nuclear family: the increasing importance of multigenerational bonds, Journal of Marriage and the Family 63(1): 1-16.

Bian, F., J. R. Logan, and Y. Bian. 1998. Intergenerational relations in urban China: proximity, contact, and help to parents, Demography 35: 115-124.

Borjas, G. J. 1998. To ghetto or not to ghetto: ethnicity and residential segregation, Journal of Urban Economics 44: 228-253.

Boyle, P., K. Halfacree, and V. Robinson. 1998. Exploring Contemporary Migration. Harlow: Longman.

Choi, N. G. 2003. Coresidence between unmarried aging parents and their adult children: who moved in with whom and why?, Research on Aging 25: 384-404.

Clark, R. L., and D. A. Wolf. 1992. Proximity of children and elderly migration, in A. Rogers (Ed.), Elderly Migration and Population Redistribution. London: Belhaven Press, pp. 77-96.

Cooke, T. J. 2003. Family migration and the relative earnings of husbands and wives, Annals of the Association of American Geographers 93: 338-349. 
Dahmann, D. 1982. Locals and Cosmopolitans: Patterns of Spatial Mobility during the Transition from Youth to Early Adulthood. Research Paper 204. Chicago: University of Chicago, Department of Geography.

DaVanzo, J. 1981. Repeat migration, information costs, and location-specific capital, Population and Environment 4: 45-73.

Dieleman, F. M., and R. J. Schouw. 1989. Divorce, mobility and housing demand, European Journal of Population 5: 235-252.

Dykstra, P.A., M. Kalmijn, T. C. M. Knijn, A. E. Komter, A. C. Liefbroer, and C. H. Mulder. 2005. Codebook of the Netherlands Kinship Panel Study, a Multi-Actor, Multi-Method Panel Study on Solidarity in Family Relationships, Wave 1. NKPS Working Paper No. 4. The Hague: Netherlands Interdisciplinary Demographic Institute.

Feijten, P. 2005. Life Events and the Housing Career: A Retrospective Analysis of Timed Effects. Delft: Eburon.

Fransson, U., and L. Teeland. 2004. Changes in the residential proximity of elderly mothers to their nearest adult child, in Housing: Growth and Regeneration. ENHR Conference, July 2004, Cambridge, England, pp. 1-15.

Ganzeboom, H. B. G., P. M. De Graaf, and D. J. Treiman. 1992. A standard international socio-economic index of occupational status, Social Science Research 21(1): 1-56.

Glaser, K., and C. Tomassini. 2000. Proximity of older women to their children: a comparison of Britain and Italy, The Gerontologist 40: 729-737.

Heckman, J. 1979. Sample selection bias as a specification error, Econometrica 47: $153-161$.

Helderman, A. C., M. Van Ham, and C. H. Mulder. 2006. Migration and home ownership, Tijdschrift voor Economische en Sociale Geografie 97: 111-125.

Ingersoll-Dayton, B., M. B. Neal, J. H. Ha, and L. B. Hammer. 2003. Redressing inequity in parent care among siblings, Journal of Marriage and the Family 65: 201-212.

Klein Ikkink, K., T. van Tilburg, and K. C. P. M. Knipscheer. 1999. Perceived instrumental support exchanges in relationships between elderly parents and their adult children: normative and structural explanations, Journal of Marriage and the Family 61: 831-844. 
Lee, G. R., J. W. Dwyer, and R .T. Coward. 1990. Residential location and proximity to children among impaired elderly parents, Rural Sociology 55: 579-589.

Lin, G., and P. A. Rogerson. 1995. Elderly parents and the geographic availability of their adult children, Research on Aging 17: 303-331.

Long, L. H. 1972. The influence of number and ages of children on residential mobility, Demography 9(3): 371-382.

Longino, C. F., D. J. Jackson, R .S. Zimmerman, and J. E. Bradsher. 1991. The second move: health and geographic mobility, Journal of Gerontology 46: 218-224.

Malmberg G., and A. Pettersson. 2007. Distance to elderly parents: Analyses of Swedish register data. Demographic Research 17(23): 679-704. www.demographic-research.org/Volumes/Vol17/23/default.htm.

Mincer, J. 1978. Family migration decisions, The Journal of Political Economy 86(5): 749-773.

Mulder, C. H., and M. Kalmijn. 2006. Geographical distances between family members, in P. A. Dykstra, M. Kalmijn, T. Knijn, A. Komter, A. Liefbroer and C. H. Mulder (Eds.), Family Solidarity in the Netherlands. Amsterdam: Dutch University Press, pp. 43-61.

Mulder, C. H., and M. Wagner. 1993. Migration and marriage in the life course: a method for studying synchronized events, European Journal of Population 9(1): $55-76$.

Rogerson, P. A., J. A. Burr, and G. Lin. 1997. Changes in geographic proximity between parents and their adult children, International Journal of Population Geography 3(2): 121-136.

Rogerson, P. A., R. H. Weng, and G. Lin. 1993. The spatial separation of parents and their adult children, Annals of the Association of American Geographers 83(4): $656-671$.

Rossi, A. S., and P. H. Rossi. 1990. Of Human Bonding: Parent-Child Relations across the Life Course. New York: Aldine de Gruyter.

Sarkisian, N., and N. Gerstel. 2004. Explaining the gender gap in help to parents: the importance of employment, Journal of Marriage and the Family 66(2):431-451.

Serow, W. J., and D. F. Sly. 1991. Geographic mobility of the elderly in industrialized societies, in Lutz (Ed.), Future Demographic Trends in Europe and North America: What Can We Assume Today? London: Academic Press, pp. 399-419. 
Shelton, N., and E. Grundy. 2000. Proximity of adult children to their parents in Great Britain, International Journal of Population Geography 6(3): 181-195.

Silverstein, M. 1995. Stability and change in temporal distance between elderly and their children, Demography 32(1): 29-45.

Sjaastad, L. A. 1962. The costs and returns of human migration, The Journal of Political Economy 70(Supplement): 80-93.

Spitze, G., and H. Logan. 1990. Sons, daughters and intergenerational social support, Journal of Marriage and the Family 52: 420-430.

Tomassini, C., D. A. Wolf, and A. Rosina. 2003. Parental housing assistance and parent-child proximity, Journal of Marriage and the Family 65(3): 700-715.

Van Diepen, A. and C. H. Mulder. 2006. Afstand tot familieleden en verhisgedrag van ouderen [Distance to family members and relocations of older people], Tijdschrijft voor Sociologie 27: 235-262.

Warnes, A. M. 1986. The residential mobility histories of parents and children, and relationships to present proximity and social integration, Environment and Planning A 18: 1581-1594.

Yerden, I. 2000. Traditie, verwantschapsrelaties, migratie en verzorging van Turkse ouderen in Nederland [Tradition, kinship relations, migration and care for Turkish elderly in the Netherlands]. Amsterdam: Het Spinhuis.

Zavodny, M. 1999. Determinants of recent immigrants' location choices, International Migration Review 33: 1014-1030. 
Michielin \& Mulder: Geographical distances between adult children and their parents in the Netherlands 